\title{
Influence of Obesity and Gender on the Postural Stability during Upright Stance
}

\author{
Nora S. Cruz-Gómez ${ }^{\mathrm{a}}$ Georgina Plascencia ${ }^{\mathrm{b}}$ Laura A. Villanueva-Padrón ${ }^{\mathrm{a}}$ \\ Kathrine Jáuregui-Renaud ${ }^{a}$ \\ a Unidad de Investigación Médica en Otoneurología,

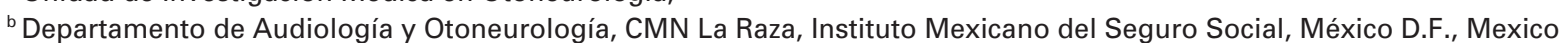

\section{Keywords \\ Obesity · Postural stability · Gender · Body weight}

\section{Summary}

Objective: To assess the influence of BMI group (lean/ overweight/obese) and gender on the postural sway of adults and adolescents during quiet upright stance. Methods: 90 women and 90 men, aged 12 to 67 years old, accepted to participate. The center of pressure during quiet upright stance was recorded using a force platform, during 4 conditions (eyes open/closed on hard/ soft surface). Statistical analysis was performed using multivariate analysis of covariance. Results: During recordings on hard surface, closing the eyes produced a larger increase of sway on obese subjects than on lean and overweight subjects, with a larger increase on the length and the area of sway. Although gender differences were found during the four sensory conditions, no interaction was observed between the BMI group and the gender. These results were not related to the age of the subjects. Conclusion: Compared to non-obese subjects, the postural stability of obese subjects may be more vulnerable when vision is not available, with no influence of the gender.

\section{Introduction}

The ability to stand upright is important by itself and as a precursor to initiation of several daily life activities. Balance control during upright stance is dependent on sensory inputs from somatosensory, visual and vestibular systems to generate appropriate motor responses [1]. Biomechanically, static balance can be defined as the ability to maintain the body's center of gravity within the limits of stability determined by the base of support. Upright quiet stance is thought to be maintained primarily through the ankle torque in the anterior-posterior plane, and the hips in the lateral-lateral plane. Recordings of the center of pressure, by a static force platform, are used to estimate body sway. The displacement velocity of the center of pressure is considered to be the most informative measurement [2] which can be estimated by the length of sway during a particular recording period. To study how sensory information contributes to postural control, a common experimental technique is to remove or attenuate a particular sensory modality and to measure how this changes sway behavior. Removing sensory information in a healthy adult population typically leads to an increase in sway [3].

Balance is related to the inertial forces acting on the body and the inertial characteristics of body segments. Morphologic characteristics, such as body weight, have an influence on postural stability [4-6]. Evidence suggests that body weight may be an important risk factor for falling [7-8]. Increased body mass seems to produce instability [7]. Patients with BMI greater than $30 \mathrm{~kg} / \mathrm{m}^{2}$ maintain shorter times in balance and longer times unbalanced as compared with nonobese individuals [9]. Additionally, after weight loss measures of static postural stability in obese subjects improve [10].

Obesity also modifies the body geometry by adding mass to different regions of the body, which imply morphological differences between males and females [11]. However, studies on the influence of gender on postural stability during quiet standing have reported contradictory findings. In children, gender differences have been observed related to morphologic differences $[12,13]$. In healthy adults, though some stud-

\section{KARGER}

Fax +497614520714

Information@Karger.de

www.karger.com (c) 2011 S. Karger GmbH, Freiburg

$1662-4025 / 11 / 0043-0212 \$ 38.00 / 0$

Accessible online at:

www.karger.com/ofa
Dr. Kathrine Jáuregui-Renaud

Unidad de Investigación Médica en Otoneurología

P.B. Edificio C Salud en el Trabajo, Centro Médico Nacional siglo XXI

Av Cuauhtemoc 330 Colonia Doctores CP 06720. México D.F., Mexico

Tel./Fax +52 5556276900

kathrine.jauregui@imss.gob.mx 
ies have shown no differences related to gender [14-17], others support that men sway more than women [18-20]. A representative nationwide sample of 7,979 Finnish subjects, aged $\geq 30$ years, showed that males tend to have more pronounced sway than females, and the difference increase in the older age groups [20].

Although obesity has shown to be related with impaired postural balance, studies evaluating the interaction between body mass index and gender on the postural sway of healthy adults are scarce. The aim of this study was to assess the influence of BMI group (lean/overweight/obese) and gender on the postural sway of healthy adults and adolescents during the 4 basic conditions of static posturography (eyes open/closed on hard/soft surface) [21].

\section{Material and Methods}

The study was approved by the Local Research and Ethics Committee and thus meets the standards of the Declaration of Helsinki in its revised version of 1975 and its amendments of 1983, 1989 and 1996. 180 subjects (90 women, 90 men) volunteered to participate. They were inhabitants of the same urban area, with regular access to the same health care system. They were included in the study by consecutive sampling, whenever they fulfilled the selection criteria. All of them reported having good health with no medication. They were evaluated regularly by their family physician and denied previous diagnosis or clinical manifestations of diabetes mellitus; none of them reported practicing sports regularly or had a his tory or clinical evidence of neurological, vestibular or orthopedic disease. Evaluation by a neuro-otologist showed no evidence of major neurological deficit or central/peripheral vestibular disease; similarly, evaluation by an physical medicine physician, which was mainly focused on the lower extremities and vertebral column, showed no major musculoskeletal abnormalities or movement limitation or general sensory deficiency (no vibrametry was performed).

The participants were between 12 and 67 years old $(35.8 \pm 12.1$ years, mean \pm SD) (table 1$)$. Since evidence support that adult-like use of sensory information is evident at the age of 12 [22], subjects younger than 12 years old were not included in the study. Men and women had a similar age and BMI, but obesity was more frequent among women while overweight was more frequent among men (table 1).

According to their BMI, subjects were classified in 3 groups: lean, overweight and obese. Among children and adolescents, overweight was considered as BMI $=85$ th to 95 th percentile and obesity as BMI $>95$ th percentile [23]; among adults overweight was considered as BMI $=25$ to $<30 \mathrm{~kg} / \mathrm{m}^{2}$ and obesity as BMI $>30 \mathrm{~kg} / \mathrm{m}^{2}$ [24]. Lean subjects $(\mathrm{n}=74)$ were $32 \pm 12$ years old, overweight subjects $(\mathrm{n}=71)$ were $37 \pm 11$ years old, and obese subjects $(\mathrm{n}=35)$ were $40 \pm 12$ years old. Although, age distribution by decade of life was similar between genders (table 1), lean subjects were significantly younger than obese subjects (ANOVA, and Tukey test $\mathrm{p}<0.05$ ) while no age difference was found between lean subjects and overweight subjects and between overweight subjects and obese subjects (ANOVA and Tukey test, $\mathrm{p}>0.05$ )

\section{Procedures}

Body sway during quiet upright stance was recorded at $40 \mathrm{~Hz}$ using a force platform (Posturolab 40/16 Medicapteurs, Cedex, France); each trial lasted $25.6 \mathrm{~s}$, during this period, subjects were asked to stand upright and barefoot on the platform as still as possible with arms at their sides. Recordings were made under 4 conditions, while adding or not a layer of foam rubber ( $5 \mathrm{~cm}$ thick, density of $2.5 \mathrm{pcf}$ ) to the base of support, with
Table 1. General characteristics of the 90 men and 90 women who participated in the study

\begin{tabular}{llll}
\hline Characteristic & Men & Women & $\begin{array}{l}\text { p value when } \\
\leq 0.05\end{array}$ \\
\hline Weight, kg & $74.2 \pm 12.4$ & $64.6 \pm 11.4$ & $<0.001$ \\
Height, cm & $168.9 \pm 6.6$ & $155.3 \pm 5.7$ & $<0.001$ \\
BMI, kg/m ${ }^{2}$ & $25.97 \pm 3.73$ & $26.83 \pm 4.77$ & - \\
Lean, \% & 41 & 37 & - \\
Overweight, \% & 48 & 33 & $<0.05$ \\
Obese, \% & 11 & 30 & $<0.01$ \\
Age, years & $34.9 \pm 12.27$ & $36.76 \pm 12.02$ & - \\
12-20 years, \% & 12 & 8 & - \\
21-30 years, \% & 27 & 20 & - \\
31-40 years, \% & 25 & 33 & - \\
41-50 years, \% & 23 & 27 & - \\
$\geq 51$ years, \% & 13 & 12 & \\
\hline
\end{tabular}

the eyes open or closed [20]: condition $1=$ hard surface and eyes open; condition 2 = hard surface and eyes closed; condition 3 = soft surface and eyes open; condition 4 = soft surface and eyes closed. Before each trial, the feet were positioned according to the manufacturer reference, and small adjustments were made online. Recordings with the eyes closed were obtained just after acquiring the data with the eyes open, without moving the feet. During each condition, the oscillation of the center of pressure was evaluated by the following measurements: the length, the area, the length as a function of the area, the variance of the velocity displacement as a function of the anterior-posterior position, the anteriorposterior position and the lateral-lateral position.

Comparison of the general characteristics of men and women was performed using $\mathrm{t}$ test, $\mathrm{t}$ test for proportions and analysis of variance. Multivariate analysis of covariance was performed for each surface condition (hard/soft surface) to evaluate the main effects and the interactions of the gender and the BMI group (as independent factors) and the age of the subjects (as a covariate) on the repeated measures of postural sway, with the eyes open or closed. Significance was set at 0.05. Calculations were performed using CSS software (Statsoft, Tulsa, OK, USA).

\section{Results}

\section{Hard Surface}

\section{Main Effects}

The effect of the BMI group (lean/overweight/obese) was observed on the length, the area and the length as a function of the area (MANCOVA, $\mathrm{p}<0.03$. When the eyes were closed, obese subjects showed a longer length and a larger area of sway than lean and overweight subjects (fig. 1). Compared to women, men had a longer length of oscillation within a similar area when the eyes were open and a more anterior position of the center of pressure either with the eyes open or closed (MANCOVA, p < 0.02) (table 2). No age effects were observed during the recordings on hard surface. 


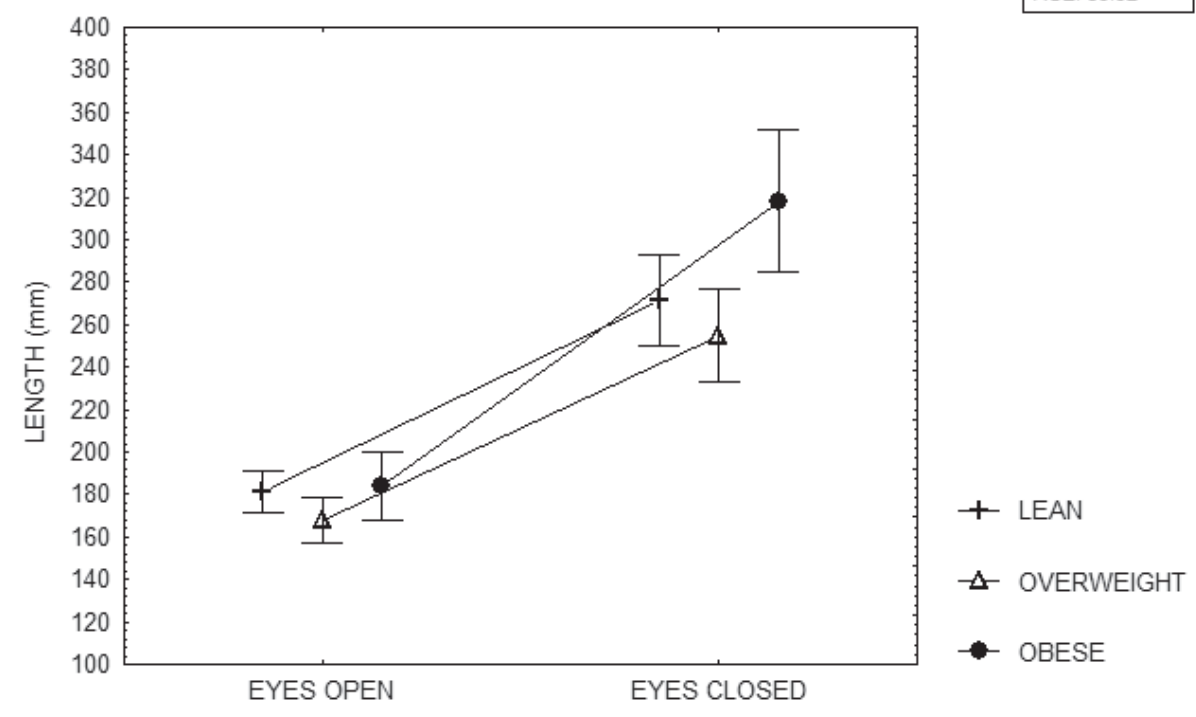

Fig. 1. Mean and standard error of the mean, of the length (A) and the area (B) of oscillation of the centre of pressure of 90 women and 90 men, computed at their mean age, according to their BMI, during recordings on hard surface, either with their eyes open or closed.
$B$

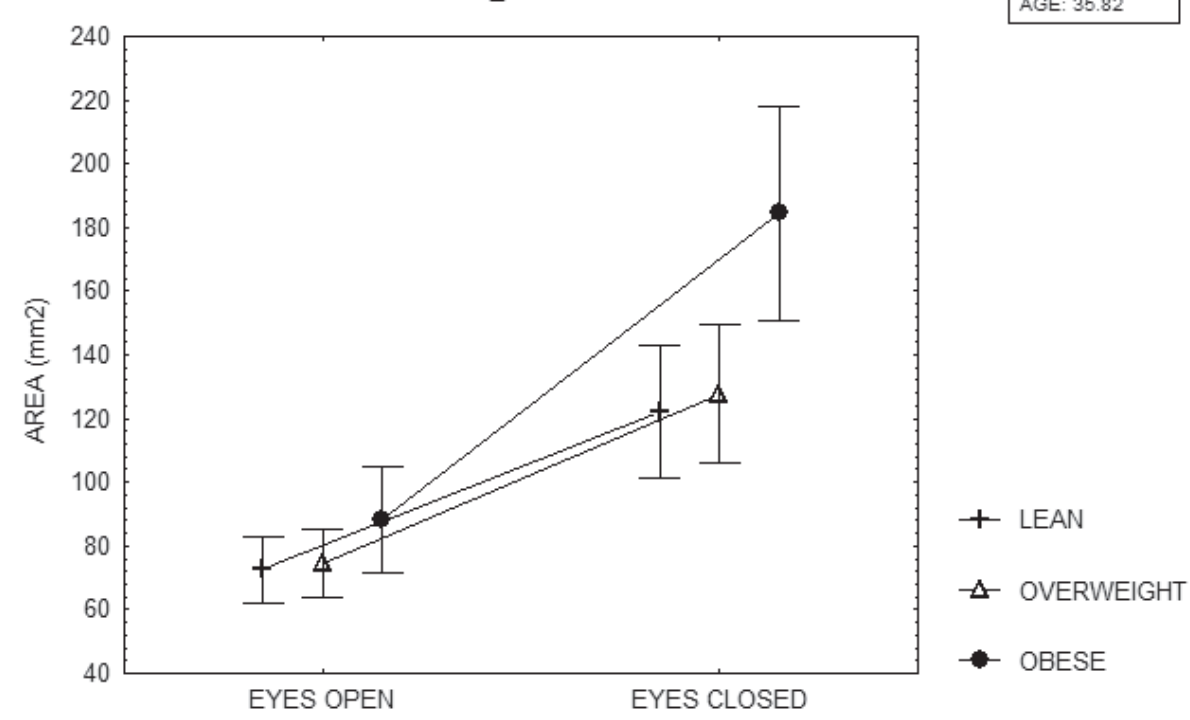

\section{Interactions}

No interaction was observed between BMI group and gender (fig. 2). However, the BMI group showed interaction with the visual condition on the length and the area of sway (MANCOVA, $\mathrm{p}<0.02$ ). Closing the eyes produced a larger increase of sway in obese subjects than in lean and overweight subjects (fig. 1). Gender showed interaction with the visual condition on the average anterior-posterior position of the center of pressure, the variance of the velocity as a function of the anterior-posterior position of the center of pressure and the length as a function of the area (MANCOVA, $\mathrm{p}<0.05$ ). When closing the eyes, women showed a larger increase of the variance of the velocity displacement as a function of the anterior-posterior position of the center of pressure and of the length of the sway within the same area than men.
Soft Surface

\section{Main Effects}

The BMI group showed an effect only on the length as a function of the area of sway (MANCOVA, $\mathrm{p}<0.05$ ). However, the gender had influence on most of the measurements of sway (MANCOVA, p < 0.02), except on the area of oscillation and the lateral-lateral position of the center of pressure; compared to women, men had a longer length and a more anterior position of the center of pressure, showing a larger ratio of the length as a function of the area, with either eyes open or eyes closed condition (table 2). When the eyes were closed, the age had an influence on the length and the length as a function of the area (MANCOVA, $\mathrm{p}=0.05$ ). 
Table 2. Mean \pm SD of the sway measurements described by gender and by study condition

(eyes open/closed and hard/soft surface)

\begin{tabular}{|c|c|c|c|c|}
\hline \multirow[t]{2}{*}{ Variables } & \multicolumn{2}{|l|}{ Eyes open } & \multicolumn{2}{|l|}{ Eyes closed } \\
\hline & $\operatorname{men}(\mathrm{n}=90)$ & women $(\mathrm{n}=90)$ & $\operatorname{men}(\mathrm{n}=90)$ & women $(\mathrm{n}=90)$ \\
\hline \multicolumn{5}{|l|}{ Hard surface } \\
\hline Length, mm & $188.2 \pm 46.2$ & $165.9 \pm 38.96$ & $281 \pm 99$ & $267.8 \pm 84.1$ \\
\hline Area, $\mathrm{mm}^{2}$ & $80 \pm 43.9$ & $72.37 \pm 45.12$ & $134.6 \pm 94.2$ & $134.8 \pm 87.9$ \\
\hline $\mathrm{X}^{\mathrm{a}}$ position, $\mathrm{mm}$ & $-0.9 \pm 8.5$ & $-1.5 \pm 6.08$ & $-0.87 \pm 9.2$ & $-1.5 \pm 6.7$ \\
\hline $\mathrm{Y}^{\mathrm{b}}$ position, $\mathrm{mm}$ & $28.8 \pm 22.2$ & $14.05 \pm 15.75$ & $30.2 \pm 22.7$ & $18.1 \pm 15.3$ \\
\hline Average velocity, $\mathrm{mm} / \mathrm{s}$ & $7.3 \pm 1.8$ & $6.48 \pm 1.52$ & $10.9 \pm 3.8$ & $10.4 \pm 3.3$ \\
\hline Length as a function of area & $0.44 \pm 0.1$ & $0.39 \pm 0.8$ & $0.51 \pm 0.15$ & $0.49 \pm 0.14$ \\
\hline $\begin{array}{l}\text { Variance of the velocity as a function } \\
\text { of } Y^{b} \text { position }\end{array}$ & $-6.32 \pm 8.55$ & $-2.8 \pm 2.81$ & $1.53 \pm 3.01$ & $1.86 \pm 2.92$ \\
\hline \multicolumn{5}{|l|}{ Soft surface } \\
\hline Length, mm & $229.31 \pm 61.04$ & $199.4 \pm 50.3$ & $395.2 \pm 121.9$ & $340.8 \pm 102.9$ \\
\hline Area, $\mathrm{mm}^{2}$ & $118.8 \pm 57.0$ & $107.36 \pm 60.2$ & $280.2 \pm 145.3$ & $277.1 \pm 175.5$ \\
\hline $\mathrm{X}^{\mathrm{a}}$ position, $\mathrm{mm}$ & $2.82 \pm 9.87$ & $1.03 \pm 7.9$ & $1.6 \pm 10.2$ & $0.72 \pm 9$ \\
\hline $\mathrm{Y}^{\mathrm{b}}$ position, $\mathrm{mm}$ & $37.31 \pm 21.3$ & $26.4 \pm 15.1$ & $37.7 \pm 21.7$ & $28.07 \pm 15$ \\
\hline Average velocity, $\mathrm{mm} / \mathrm{s}$ & $8.9 \pm 2.3$ & $7.8 \pm 1.9$ & $15.4 \pm 4.7$ & $13.31 \pm 4.02$ \\
\hline Length as a function of area & $0.52 \pm 0.13$ & $0.46 \pm 0.1$ & $0.64 \pm 0.18$ & $0.56 \pm 0.15$ \\
\hline $\begin{array}{l}\text { Variance of the velocity as a function } \\
\text { of } \mathrm{Y}^{\mathrm{b}} \text { position }\end{array}$ & $-7.28 \pm 8.87$ & $-3.61 \pm 5.25$ & $4.77 \pm 3.8$ & $4.52 \pm 3.31$ \\
\hline
\end{tabular}

\section{Interactions}

No interaction was observed between the BMI group and the gender (fig. 2). However, the BMI group showed interaction with the visual condition (eyes open / eyes closed) on the area of oscillation (MANCOVA, $\mathrm{p}=0.02$ ). A larger increase of the sway area was observed in overweight subjects when compared with lean subjects. Gender showed interaction with the visual condition on the variance of the velocity displacement as a function of the anterior-position of the center of pressure (MANCOVA, $\mathrm{p}=0.01$ ). The difference between genders that was observed when the eyes were open was not evident when the eyes were closed.

\section{Discussion}

Obese subjects have a higher prevalence of falling and ambulatory stumbling as well as a lower quality of life in multiple health domains than their normal-weight counterparts [25]. In male subjects, stepwise multiple regression analysis of force platform recordings have shown that body weight may account for about half of the variance of balance stability [7]. On computerized baropodometric recordings, during quiet standing, obese subjects have an increase of the peak pressure on forefoot and plantar ground contact area compared to control and overweight subjects [26]. In the present study, obesity was related to a decrease in postural stability when vision was not available. Closing the eyes while standing on a hard surface had a larger destabilizing effect on obese subjects, than in lean and overweight subjects, without any interaction with gender. This finding supports that obese subjects may be more dependent on vision to control balance. In addition, after closing the eyes, the increase of sway was similar when recordings were made either on hard or on soft surface, which suggest that in this study obese subjects used their somatosensation to control posture differently than lean and overweight subjects. However, since no electrophysiological studies or exhaustive clinical evaluations were performed to identify neural dysfunction, mild neuropathy cannot be excluded from interfering with these results.

A comparative study assessing the effect of body weight increases on posturography recordings of 44 adults (22 males and 22 females) had shown that increased body mass seems to produce anterior-posterior instability in both genders and medial-lateral destabilization only in males [11]. In this study, the evaluation of 180 adults and adolescents (90 males and 90 females) under different sensory conditions showed gender-associated differences during the four sensory conditions, mainly related to the anterior-posterior position and displacement of the center of pressure. However, no interaction with the BMI was observed. The results suggest that the gender difference could be related to differences in the use of the ankle torque [27-28] and muscle strength/performance, which were not considered in this study. 

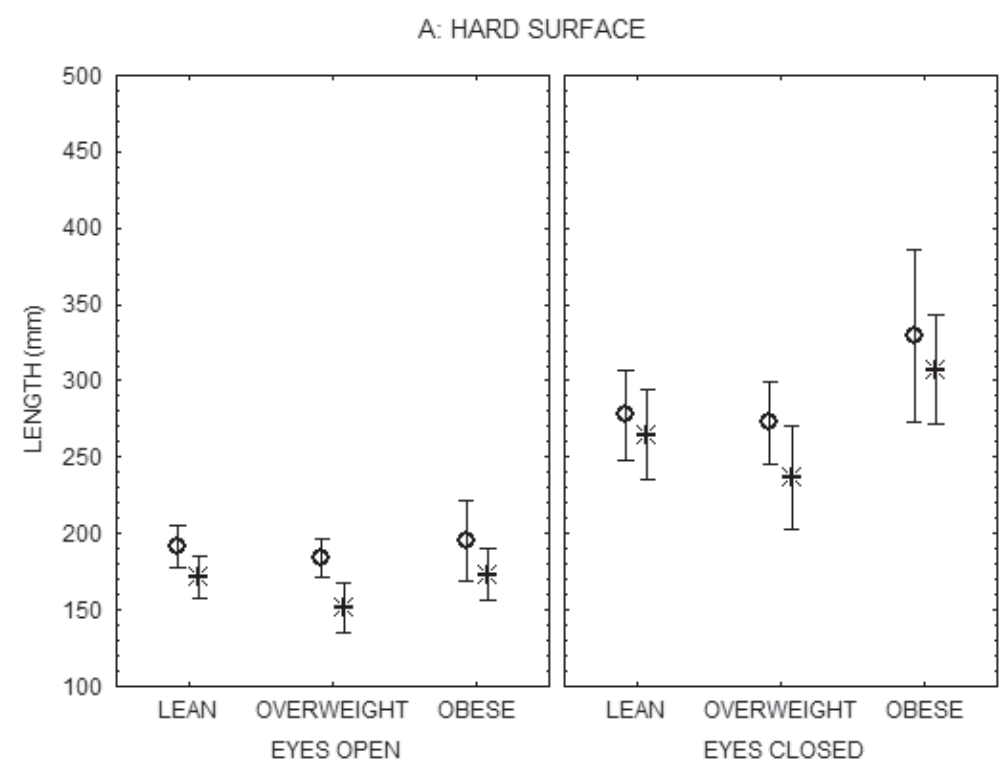

Fig. 2. Mean and standard error of the mean of the length of oscillation of the centre of pressure of lean, overweight and obese subjects, computed at their mean age, according to their gender, during recordings on soft surface (A) and hard surface (B), either with their eyes open or closed.

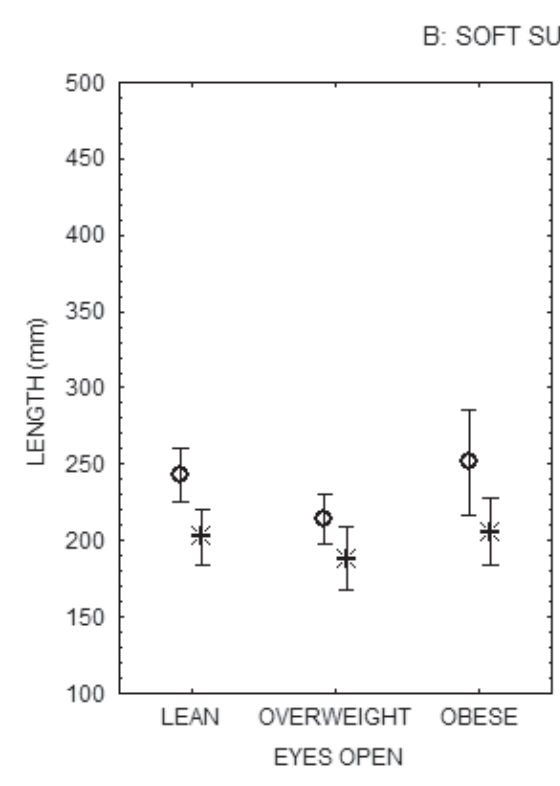
AGE: 35.82

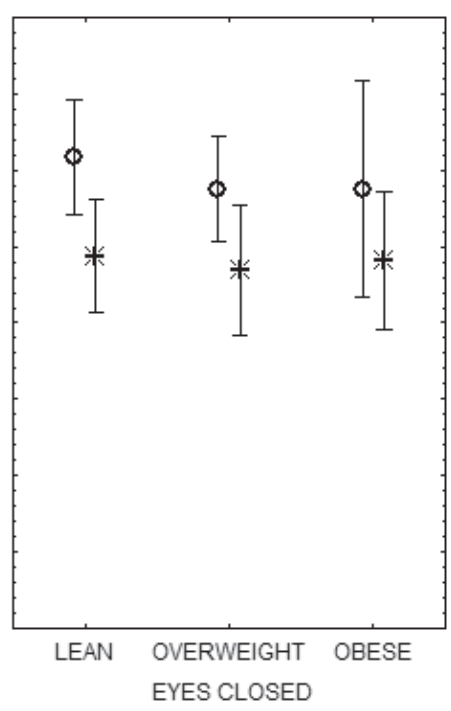

$\circ$ Men

* Women

$\circ$ Men

* Women

The influence of age during the recordings performed on soft surface is consistent with the evidence showing that sway increases with increasing age [16,20], with an increased dependence on vision $[15,29]$. Additionally, dependence on vision may increase when reliable pressoreceptor information is removed $[15,30]$. In this study, during recordings on soft surface with the eyes closed older subjects swayed more to maintain the center of pressure within a similar area than younger subjects, which also imply a larger expenditure of energy to maintain stability. The finding that the main effect of age on postural stability was observed when pressoreceptor information was distorted (soft surface) while the main effect of BMI group was observed when pressoreceptor information was available (hard surface), suggests that the difference observed between obese subjects and lean/ overweight subjects might not have been strongly influenced by age.

In conclusion, the postural stability during upright stance of obese subjects, compared to non-obese subjects, may be more dependent on vision, with no interaction with the gender. More studies are needed to identify the practical consequences of these findings on daily life activities (e.g. circumstances of falls and other incidents).

\section{Disclosure Statement}

The authors declare no conflict of interest. 


\section{References}

1 Forssberg H, Nashner LM: Ontogenic development of postural control in man: adaptation to altered support and visual conditions during stance. J Neurosci 1982;2:545-552.

2 Raymakers JA, Samson MM, Verhaar HJ: The assessment of body sway and the choice of the stability parameter(s). Gait Posture 2005;21:48-58.

3 Woollacott MH, Shumway-Cook A, Nashner L: Aging and postural control: changes in sensory organization and muscular coordination. Int J Aging Hum Dev 1986;23:97-114.

4 Bryant EC, Trew ME, Bruce AM, Kusima RM, Smith AW: Gender differences in balance performance at the time of retirement. Clin Biomech (Bristol,Avon) 2005;20:330-335.

$\checkmark 5$ Kitabayashi T, Demura SH, Noda M, Yamada T: Gender differences in body-sway factors of center of foot pressure in static upright posture and under the influence of alcohol intake. J Physiol Anthropol Appl Human Sci 2004;23:111-118.

6 Farenc I, Rouger P, Berger L: The influence of gender and body characteristics on upright stance. Ann Hum Biol 2003;30:279-294.

$\checkmark 7$ Hue O, Simoneau M, Marcotte J, Berrigan F, Doré J, Marceau P, Marceau S, Tremblay A, Teasdale N: Body weight is a strong predictor of postural stability. Gait Posture 2007;26:32-38.

8 Singh D, Park W, Levy MS, Jung ES: The effects of obesity and standing time on postural sway during prolonged quiet standing. Ergonomics 2009; 52:977-986.

$\checkmark 9$ Greve J, Alonso A, Bordini ACPG, Camanho GL: Correlation between body mass index and postural balance. Clinics 2007;62:717-720.

10 Teasdale N, Hue O, Marcotte J, Berrigan F, Simoneau M, Doré J, Marceau P, Marceau S, Tremblay A: Reducing weight increases postural stability in obese and morbid obese men. Int J Obes (Lond) 2007;31:153-160.
1 Menegoni F, Gali M, Tacchini E, Voismara L, Cavigiolo M, Capodaglio P: Gender-specific effect of obesity on balance. Obesity (Silver Spring) 2009;17:1951-1956.

12 Allard P, Nault ML, Hinse S, LeBlanc R, Labelle $\mathrm{H}$ : Relationship between morphologic somatotypes and standing posture equilibrium. Ann Hum Biol 2001;28:624-633.

13 Lee AJ, Lin WH: The influence of gender and somatotype on single-leg upright standing postural stability in children. J Appl Biomech 2007;23: 173-179.

14 Era P, Schroll M, Ytting H, Gause-Nilsson I, Heikkinen E, Steen B: Postural balance and its sensorymotor correlates in 75-year-old men and women: a cross-national comparative study. J Gerontol A Biol Sci Med Sci 1996;51:M53-63.

15 Colledge NR, Cantley P, Peaston I, Brash H, Lewis S, Wilson JA: Aging and balance: the measurement of spontanaeous sway by posturography. Gerontology 1994;40:273-278.

16 Røgind H, Lykkegaard JJ, Bliddal H, DanneskioldSamsøe B: Postural sway in normal subjects aged 20-70 years. Clin Physiol Funct Imaging 2003; 23:171-176.

17 Hageman PA, Leibowitz JM, Blanke D: Age and gender effects on postural control measures. Arch Phys Med Rehabil 1995;76:961-965.

18 Kollegger H, Baumgartner C, Wöber C, Oder W, Deecke L: Spontaneous body sway as a function of sex, age, and vision: posturographic study in 30 healthy adults. Eur Neurol 1992;32:253-259.

19 Ekdahl C, Jarnlo GB, Andersson SI: Standing balance in healthy subjects. Evaluation of a quantitative test battery on a force platform. Scand J Rehabil Med 1989;21:187-195.

20 Era P, Sainio P, Koskinen S, Haavisto P, Vaara M, Aromaa A: Postural balance in a random sample of 7,979 subjects aged 30 years and over. Gerontology 2006;52:204-213.
1 Norré ME: Sensory interaction testing in platform posturography. J Laryngol Otol 1993;107:496-501.

22 Peterson ML, Christou E, Rosengren KS: Children achieve adult-like sensory integration during stance at 12 years old. Gait Posture 2006;23:455-463.

23 Barlow SE, Dietz WH: Obesity evaluation and treatment: expert committee recommendations. The Maternal and Child Health Bureau, Health Resources and Services Administration and the Department of Health and Human Services. Pediatrics 1998;102:E29.

24 Expert Panel on the Identification, Evaluation, and Treatment of Overweight in Adults: Clinical guidelines on the identification, evaluation, and treatment of overweight and obesity in adults: executive summary. Am J Clin Nutr 1998;68:899-917.

25 Fjeldstad C, Fjeldstad A, Acree L, Nickel K, Gardner A: The influence of obesity on falls and quality of life. Dyn Med 2008;27:4.

26 Fabris SM, Valezi AC, de Souza SA, Faintuch J, Cecconello I, Junior MP: Computerized baropodometry in obese patients. Obes Surg 2006; 16:1574-1578.

27 Lindle RS, Metter EJ, Lynch NA, Fleg JL, Fozard JL, Tobin J, Roy TA, Hurley BF: Age and gender comparisons of muscle strength in 654 women and men aged 20-93 yr. J Appl Physiol 1997;83:15811587.

28 Jan MH, Chai HM, Lin YF, Lin JC, Tsai LY, Ou YC, Lin DH: Effects of age and sex on the results of an ankle plantar-flexor manual muscle test. Phys Ther 2005;85:1078-108

29 Poulain I, Giraudet G: Age-related changes of visual contribution in posture control. Gait Posture 2008;27:1-7.

30 Wolfson L, Whipple R, Derby CA, Amerman P, Nashner L: Gender differences in the balance of healthy elderly as demonstrated by dynamic posturography. J Gerontol 1994;49:M160-167. 